\title{
Privacidade na comunicação eletrônica
}

\section{Ives Gandra da Silva Martins}

Professor Emérito das Universidades Mackenzie, Paulista e Escola de Comando e Estado Maior do Exército, presidente do Conselho de Estudos Jurídicos da Federação do Comércio do Estado de São Paulo e do Centro de Extensão Universitária (CEU).

\section{Rogério Vidal Gandra da Silva Martins}

Advogado em São Paulo e pós-graduando em Direito tributário pelo Centro de Extensão Universitária.

\section{Resumo}

O trabalho aborda os problemas suscitados pela universalização eletrônica e as dificuldade de aplicação de medidas jurídicas de controle, enfocadas no direito à privacidade na comunicação eletrônica.

\section{Palavras-chave}

Comunicação eletrônica; Direito autoral; Informação.

\section{Privacy in electronic communication}

\section{Abstract \\ This paper discusses the problems originated by the electronic universalization and the difficulties of application of juridical measures of control, with reference to the rights of privacy in communication.}

\section{Keywords}

Electronic communication; Copyrights; Information.
Muito se tem escrito sobre a informática e os problemas jurídicos que suscita em variadas áreas por sua universalização e pelo fato de, no mais das vezes, o fenômeno legal ser um fenômeno nacional e, portanto, de pouca abrangência para a regulação do novo campo de comunicação.

A grande questão que se tem colocado é saber como se deve reger, de forma uniforme, a comunicação eletrônica, a partir de regramentos jurídicos pertinentes a cada nação ou, ainda, como aplicar os acordos, tratados e convênios internacionais assinados sobre a informática, quando os pontos de transmissão e recepção se encontrem fora dos países signatários ${ }^{1}$.

Para os autores, a questão do controle da informática assemelha-se muito ao controle da circulação da moeda e dos ativos financeiros, dos quais mais de 15 trilhões encontram-se fora de controle de qualquer banco central de países civilizados, em face de transitarem por paraísos fiscais, com regulação própria e protetora de tais recursos, porque a eles interessa esta riqueza disponível ${ }^{2}$.

Da mesma forma que a legislação punitiva do mercado interno contra a lavagem do dinheiro é insuficiente e precária para surtir efeitos reais, qualquer controle sobre a comunicação eletrônica propicia, também, pequenos resultados, visto que dois fatores dificultam supervisão maior:

a) a possibilidade de os pontos de ignição do sistema encontrarem-se fora do alcance dos países com regulação jurídica possível;

b) os gênios da informática dificultarem sua localização, sobre poderem ter acesso, quebrar sistemas de segurança, invadir e destruir informações alheias, com razoável freqüência e impunidade ${ }^{3}$.

Em outras palavras, no mundo da comunicação eletrônica, o "ativo financeiro" é a informação, e esta migra com velocidade surpreendente, assalta os informatizados e pode restar sem paternidade, a partir da genialidade dos que a manipulam ou do refúgio em países onde a legislação seja flexível ou pouco severa.

Por esta razão, as sucessivas diretivas da União Européia ainda são insuficientes para conter os abusos que os hackers podem gerar, sobre não ser fácil definir o tratamento tributário, concorrencial, jornalístico, comercial, econômico e pessoal que se deve dar à informática. 
Em outras palavras, a universalização da comunicação eletrônica carece de uma legislação igualmente universal de controle de todos os países, mediante disciplina jurídica idêntica e com possibilidades de intervenção supranacional de órgãos internacionais e/ou comunitários ${ }^{4}$.

A informática, em última análise, tornou-se o meio mais fácil de comunicação e veiculação de decisões, negócios, lazer, informações e correspondência privada, mas sua disciplina universal ainda não existe e não sabemos se, sem um Estado universal, será de fácil consecução.

A informática, todavia, é apenas um veículo moderno, rápido e universal de comunicação.

Entre as cláusulas pétreas da Constituição brasileira encontra-se o direito à preservação da intimidade a ensejar ações judiciais reparativas contra sua violação.

O artigo 5ํㅜㄹ inciso X, da lei suprema está assim veiculado:

"são invioláveis a intimidade, a vida privada, a honra e a imagem das pessoas, assegurado o direito à indenização pelo dano material ou moral decorrente de sua violação" ${ }^{5}$.

Um dos autores deste trabalho tem pessoalmente se manifestado contra a indústria das ações reparadoras do dano moral, que forjam lesões inexistentes, na busca de um enriquecimento sem justa causa. Uma excessiva valorização do "preço" e da dor moral, do pretium doloris, em que não há dor, nem moral, mas apenas um bom negócio, está a merecer reflexão de julgadores e juristas na busca da justa medida para o ressarcimento pecuniário devido pela violência praticada contra a privacidade e a dignidade das pessoas ${ }^{6}$.

O exagero e o artificialismo com que estas ações indenizatórias são elaboradas para a obtenção de polpudos benefícios para um dano maliciosamente alegado não afastam, todavia, a necessidade de preservação de bens supremos, que são a intimidade e a privacidade das pessoas.

Um dos autores deste trabalho, em palestra proferida e citando outros autores, assim conformou sua visão da intimidade, também aceita pelo outro co-autor e ora transcrita:

"É bem verdade que houve uma grande evolução na doutrina sobre o direito à imagem, à honra e à identidade, só não tecendo maiores comentários a respeito em face da brilhante palestra de Carlos Alberto Bittar. De qualquer forma não se pode deixar de lembrar a obra de Gotrama Gonzalez publicada na "Nova
Enciclopédia Jurídica" (tomo XI, pgs. 301 e segs., Ed. Barcelona, 1962), em que se refere a sete teorias sobre o direito à imagem (1) negativista; 2) vinculada à honra; 3) expressão do corpo; 4) direito à identidade; 5) direito à intimidade; 6) direito à liberdade e 7) patrimônio moral).

É reconhecida a evolução de um direito à honra para um direito à imagem e finalmente à identidade do ser humano com suas circunstâncias e meio em que vive, que conformam o denominado direito à personalidade. A doutrina evoluiu para mostrar que o direito à honra não compõe por inteiro a personalidade, nem a própria imagem, ou mesmo a identidade, sendo esta o complexo de atributos internos, externos e naturais que esculpem a pessoa humana.

Fábio de Matia historia: "Os especialistas alemães, na segunda metade do século XIX, cognominaram os direitos da personalidade como "Individualiatsrechte" $e$ "Personlichkeitsrechte".

São outras as denominações usadas: "Direitos essenciais ou fundamentais da pessoa, Direitos da própria pessoa, Direitos de Estado, Direitos personalíssimos".

Uma denominação bem antiga é a de direitos inatos utilizada pela Escola do Direito Natural.

Arturo Valencia Zea os chamou de "derechos de personalidado humanos".

A expressão consagrada é a "direitos da personalidade" ou então "direitos privados da personalidade".

Simón Carrejo afirma que a expressão direitos da personalidade é aceita na doutrina da atualidade por "ser más comprehensiva" (Estudos de Direito Civil, Ed. Revista dos Tribunais, p. 102).

Sendo, pois, o direito à personalidade um bem imaterial, sempre que tal bem seja atingido há de se compreender uma justa reação do cidadão, que, todavia, não pode, a meu ver, ser uma reação de quem quer aproveitar a lesão definida para a partir dela fazer um bom negócio, risco de sua moral ou sua honra ou sua imagem não valer muito mais do que aquela da história da rapariga cuja honra tinha um preço. O "pretium doloris", como se a dor fosse redutivel a um bom punhado de dólares - ou reais -,é reduzir a meu ver o maior dos bens de uma pessoa à sua expressão mais vil, embora extremamente útil para que se possa usufruir a vida mais confortavelmente a partir do ressarcimento patrimonial de um dano moral. 
À evidência, o dano moral que implique uma perda patrimonial deve ser ressarcido pela lesão patrimonial, mas o dano moral que implique uma desfiguração de personalidade, no entender do desfigurado, só pode e deve ser ressarcido após ter o "sofredor" quantificado o volume financeiro da sua dor e ser este justo, na opinião do julgador, depois de ter ponderado todos os aspectos que determinaram o valor pecuniário demandado pela dor moral.

É interessante verificar que sempre que a dor é realmente moral não se procura tal ressarcimento na justiça, como nos casos de adultério em que o cônjuge atingido pode pedir a separação, mas raramente ingressa com a ação pertinente por dano moral.

Poder-se-ia dizer que a cópia de uma obra artística, o plágio de um livro, a reprodução sem autorização de trabalho intelectual possam representar dano moral, mas o ressarcimento aí se justifica não pelo dano moral, mas pelo crime material e pelo benefício pecuniário resultante da reprodução, devendo o intelectual furtado em suas idéias, obras ou exteriorizações materiais ser mais indenizado pela perda dos direitos por terceiros explorados do que pelo próprio dano moral. Parece-me típico caso de ressarcimento pecuniário por dano moral com implicações patrimoniais.

É de se lembrar que para alguns dos direitos da personalidade violentados há proteção tarifária com cálculos atuariais de lei que facilitam ao julgador sua aplicação. Mas tais cálculos atuariais dizem mais respeito àqueles direitos da personalidade cuja violência acarrete consequências de natureza patrimonial. E o dano moral puro não é de fácil quantificação em tabelas atuariais"'.

Tais valores são aqueles que devem ser preservados e protegidos contra os agressores, principalmente quando desfiguram publicamente a imagem das pessoas, por qualquer veículo que permita o acesso a terceiros de informações corrosivas.

É pacífico que a desfiguração pública pela imprensa torna possível a detecção dos causadores do mal, permitindo as medidas judiciais pertinentes ${ }^{8}$.

Mesmo assim, é de se perguntar se a notícia divulgada sobre homem público - que, para representar a população que nele confia, não pode esconder nada da comunidade a que serve - pode ensejar ação reparatória.

Entendemos que a privacidade a que se refere o art. 5은 inciso $\mathrm{X}$ diz respeito àquele cidadão comum, ao homem corrente, e não aos que devem representar a cidadania. Estes devem ter sua vida como um livro aberto. Os "homens públicos" - neles incluo as mulheres, para diferenciá-las daquelas em que o adjetivo indica profissão diversa - como a própria qualificação está a indicar são "públicos”, e não "privados", nada podendo esconder dos que representam ou servem.

Não sem razão, em inúmeros dispositivos, a Constituição exige "expressamente" "reputação ilibada" para o exercício de certas funções, não se devendo entender, entretanto, que tal reputação seja desnecessária para as demais. Para todos os ocupantes de funções públicas, é necessário reputação ilibada, em face de o art. 37 da Constituição Federal exigir a "moralidade" como princípio fundamental. Em visão abrangente desse princípio, não é de se admitir que as pessoas possam ser "imorais" em determinadas áreas de atuação pública e "morais" em outras ${ }^{9}$.

Para nós, fatos verdadeiros sobre homens públicos podem ser veiculados sem ferir a privacidade do cidadão e sem ensejar as ações reparadoras. Se a notícia for falsa, os meios de comunicação podem ser acionados para repararem o dano civil e também criminalmente por difamação, mas só nesta hipótese.

Pergunta-se, entretanto, se a comunicação eletrônica ensejaria os mesmos mecanismos de defesa judicial que a comunicação clássica.

A Internet tornou inexistente a privacidade de todo o cidadão que a ela tem acesso, pois sujeito a assaltos dos "predadores dos sistemas", nada obstante os esquemas de segurança e, muitas vezes, sem que o lesado tenha conhecimento de que seu sistema pessoal foi assaltado.

Mais do que isto, porque a vida social está hoje totalmente informatizada, mesmo aqueles que, nos seus sistemas particulares, garantem-se contra tais assaltos, evitando disponibilizar pela "internet" aquelas informações que entendem privadas, mediante a utilização de linhas telefônicas distintas - uma para rede interna, e outra conectada à internet -, acabam incorrendo em riscos, de vez que são levados pelas autoridades a fazer suas declarações de rendas por essa via de comunicação que não conta, nos dias de hoje, com meios de segurança suficientes. Em razão disso, todos seus ativos e operações financeiras realizados em instituições bancárias, informações sobre seus empregos, empresas e entidades com que trabalham tornamse de fácil exposição aos veículos de comunicação eletrônica.

A obtenção dolosa ou culposa dos dados pessoais de quase 2 milhões de contribuintes junto à Receita Federal, tornando esse órgão passível de ações indenizatórias por não ter sabido preservar as informações sigilosas de que dispunha sobre a vida patrimonial de seus contribuintes, 
está a demonstrar como a internet se transformou em um espaço aberto, com mecanismos insuficientes de proteção à privacidade das pessoas, exposta aos mais variados tipos de devassa ${ }^{10}$.

A questão, todavia, da desfiguração da imagem, via internet, deve merecer o mesmo tratamento privativo que aquele dos meios clássicos de comunicação, cumprindo à legislação adotar os meios para que isso se torne possível.

Hoje, por exemplo, um cidadão brasileiro tiver sua imagem atingida por comunicação emitida de países que não aderirem convenções internacionais de proteção jurídica para a área - embora de fácil e imediato acesso por todos os que quiserem receber tal imagem no país - nada obstante possa tal conduta caracterizar o dano moral ressarcível, dificilmente esse ressarcimento será possível, à falta de mecanismos jurídicos para fazê-lo.

Questão interessante é a de saber se a mera troca de informações entre pessoas, cuja "sala" não disponibilizada para terceiros é acessada e revelada por hackers, ensejaria ação contra os "provedores", visto que seriam de difícil localização os "assaltantes"? Temos sérias dúvidas, pois, tecnicamente, os provedores apenas veiculam informações, como entidades neutras.

Toda esta matéria está a merecer tratamento jurídico-legal, independentemente dos tratados e da discussão internacional, que só teria validade e eficácia se gerasse uma convenção mundial, com adesão de todos os países ${ }^{11}$.

Cremos que no Brasil, à luz da legislação vigente e da jurisprudência sobre preservação da intimidade, poderiam ser adotados os seguintes pontos de referência:

1) toda a comunicação eletrônica pública deve ter o mesmo tratamento para efeitos ressarcitórios da comunicação clássica pela imprensa;

2) toda a comunicação eletrônica privada não pode ensejar ações reparatórias - à falta de intenção de torná-las públicas -, se a publicidade se der por violação dos sistemas de segurança;

3) todo o depósito de dados desfigurativos que não são públicos, mas que não possuem sistemas de segurança, de tal forma que qualquer pessoa possa acessá-los, ensejaria os mesmos procedimentos ressarcitórios da comunicação clássica;
4) a desfiguração de imagem por informações colocadas fora da soberania das leis do país ensejaria os meios ressarcitórios clássicos, se alavancada no Brasil, cabendo aos que difundiram a imagem corroída a responsabilidade pelo ressarcimento.

Até que se cristalize uma legislação mundial de proteção à liberdade de informação e da disciplinadora da responsabilidade pertinente, parece-nos o melhor caminho para cuidar da preservação da privacidade das pessoas, no campo da informação eletrônica ${ }^{12}$.

É de se lembrar, por fim, que o Decreto no 3.505 de 13 de junho de 2000, que institui a política de segurança da informação nos órgãos e entidades da Administração Pública Federal, não infirma nenhuma das observações do presente trabalho.

\section{NOTAS}

1 Marco Aurélio Greco reconhece a difícil problemática ao dizer: "Além das repercussões na idéia de soberania e na eficácia das legislações, não se pode deixar de mencionar os reflexos que serão gerados em relação ao exercício da função jurisdicional. Por um lado, a virtualização dos bens e a mobilidade de pessoas e atividades dificultam a aplicação de provimentos judiciais, desde os cautelares (por exemplo, apreensão do conteúdo de um "site") até os ligados ao próprio conteúdo da prestação jurisdicional (sua execução).

Não apenas a eficácia dos provimentos judiciais é afetada, como, principalmente, a compreensão das realidades mundiais (portanto, que extrapolam o âmbito territorial local) passa a ser relevante para interpretar a legislação interna. Em outras palavras, além de fenômenos internacionais (por exemplo, o crime organizado) levar à necessidade de leis especiais para serem aplicadas em nosso território (por exemplo, lei de lavagem de dinheiro), surgirá o momento em que a interpretação e aplicação da legislação interna sofrerão influência da realidade externa. De fato, uma lei terá seu efetivo alcance determinado em função da interpretação que lhe for dada pelos aplicadores e juízes, e uma interpretação segundo critérios tipicamente locais (por exemplo, amplitude dos tipos penais ou atribuir sentido jurídico ou econômico a certos conceitos) podem ser a pedra de toque da eficácia ou ineficácia do dispositivo, tendo em vista o conjunto de medidas que os Estados em geral tomarem para enfrentar determinada realidade global" (Internet e Direito, Ed. Dialética, São Paulo 2000, p. 15).

${ }^{2}$ Escrevi: "Elemento que tem preocupado cada vez mais os países desenvolvidos e em desenvolvimento é o volume de dinheiro que os agentes econômicos anônimos detêm e que circulam pelo mundo inteiro, calculado em 13 trilhões de dólares ou 2 PIBs americanos.

Tais recursos, cujos titulares os governos desconhecem em parte e cujos operadores oficiais encontram-se em paraísos fiscais não controlados pelas grandes nações, são direcionados, em velocidade crescente, para os países que oferecem melhores condições de lucratividade, mas podem ser deles retirados na mesma rapidez com que lá entraram. Na medida em que a globalização da economia exige crescente abertura cambial, a movimentação de tais recursos é mais ágil, com o que os países em desenvolvimento, por exemplo, podem recebê-los em quantidade maior do que no passado, desde que garantam uma renda e ofereçam melhores condições que as dos países desenvolvidos" (Uma visão do mundo contemporâneo, Ed. Pioneira, 1996, p. 92/93). 


\section{Privacidade na comunicação eletrônica}

${ }^{3}$ Edward A. Cavazos e Gavino Morin, em 1993, já se assustavam com esta realidade: "Cyberspace has grown at an almost incredible rate over the last few years, and indications are that this rate will continue. The bulletin board phenomenon clearly indicates this growth. The first bulletin board software, written by Ward Christensen and called "CBBS", was put on line in 1978. If Christensen's board is still running, it is by no means alone, as 60,000 other systems have come on-line since then.

Networks are also growing explosively. An indication of this trend is the Internet's growth sine its beginnings in 1981. At that time, the number of host systems was 213 machines. The time of this writing, twelve years later, the number has jumped to $1,313,000$ systems connecting directly to the Internet. The dramatic rate of growth becomes evident when the numbers of hosts in 1992 - 727,000-is compared to the 1.3 million figure of 1993 .

The growth of the Internet will be further boosted by recently passed federal legislation designed to bolster the development of a digital "information infrastructure". The law, called the High Performance Computing Act, was passed in 1991. It calls for a government and industry coalition working to research the hardware and software needs for the digital equivalent of the federal highway system with computer connections linking millions of Americans.

Like the Internet, Fidonet has experienced startling growth. The original Fido BBS was released in June of 1984, and within a year 160 nodes had signed on. Today with over 22,00 nodes, Fidonet is one of the fastest growing computer networks in the world" (Ciberspace and the Law: Your Rightes and Duties in the On-line World, The MIT Press, London, England, 1996, p. 10/11).

${ }^{4}$ Lê-se no parecer do Comitê Econômico e Social da União Européia (97/C290/04) sobre uma sociedade global de informação, o seguinte: 1.3. O plano evolutivo é o resultado de "um amplo processo de reflexão sobre a sociedade da informação, que levou à identificação de 4 novos domínios prioritários":

- melhorar o contexto empresarial através da liberalização das telecomunicações, com novas acções a favor das PME;

- investir no futuro, privilegiando a escola e os jovens;

- centrar as atenções no cidadão, favorecendo igualmente a coesão e o emprego;

- considerar a importância da cooperação global, criando regras mundiais sobre acesso ao mercado, direitos de propriedade intelectual, protecção da vida privada e proteção contra utilizações ilícitas etc." (Jornal Oficial das Comunidades Européias de 29/9/97).

5 Celso Ribeiro Bastos assim o comenta: "A evolução tecnológica torna possível uma devassa da vida íntima das pessoas, insuspeitada por ocasião das primeiras declarações de direitos.

É por isto que o seu aparecimento será um pouco mais tardio.

Contudo é bom notar que também não é uma preocupação dos nossos dias. O problema já no século passado se fez eclodir, sobretudo na França, com a publicação indiscreta de fotos de artistas célebres.

Nada obstante isto, na época atual, as teleobjetivas, assim como os aparelhos eletrônicos de ausculta, tornam muito facilmente devassável a vida intima das pessoas. É certo que esta intimidade já encontra proteção em uma série de direitos individuais do tipo inviolabilidade de domicílio, sigilo da correspondência etc. ...

Sem embargo disto, sentiu-se a necessidade de proteger especificamente a imagem das pessoas, a sua vida privada, a sua intimidade.

Podemos dizer que o direito à imagem consiste no direito de ninguém ver o seu retrato exposto em público sem o seu consentimento.

Pode-se ainda acrescentar uma outra modalidade deste direito, consistente em não ser a sua imagem distorcida por um processo malévolo de montagem" (Comentários à Constituição do Brasil, vol.2, Ed. Saraiva, 1989, p. 62)

6 Álvaro Villaça lembra que: "Problema, de difícil solução, que têm enfrentado nossos Tribunais, é o da quantificação, da avaliação ou da apuração desse dano, fundado em reprimir a sensação dolorosa, sentida pela vítima do dano moral.
Essa dificuldade, entretanto, jamais foi ou poderá ser levada a que não se indenize o dano moral.

Nosso Código, por seu art. 1.553, apresenta solução genérica, para que não reste irreparado qualquer dano, quando alude a que, nos casos não previstos em lei, no tocante à liquidação de danos resultantes de atos ilícitos, a indenização dar-se-á por arbitramento" (Teoria Geral das Obrigações, Ed. Revista dos Tribunais, p. 226).

7 Palestra de Ives Gandra da Silva Martins no 2o Ciclo de Estudos de Direito Econômico, publicada no livro "Estudos de Direito Econômico", Ed. IBCB, 1994, p. 130 a 131.

8 Limongi França elenca os seguintes direitos privados da personalidade:

"1. Direito à Integridade Física:

1.1. Direito à vida e aos alimentos

1.2. Direito sobre o próprio corpo, vivo

1.3. Direito sobre o próprio corpo, morto

1.4. Direito sobre o corpo alheio, vivo

1.5. Direito sobre o corpo alheio, morto

1.6. Direito sobre partes separadas do corpo, vivo

1.7. Direito sobre partes separadas do corpo, morto;

2. Direito à Integridade Intelectual:

2.1. Direito à liberdade de pensamento

2.2. Direito pessoal de autor científico

2.3. Direito pessoal de autor artístico

2.4. Direito pessoal de inventor;

3. Direito à Integridade Moral

3.1. Direito à liberdade civil, política e religiosa

3.2. Direito à honra

3.3. Direito à honorificiência

3.4. Direito ao recato

3.5. Direito ao segredo pessoal, doméstico e profissional

3.6. Direito à imagem

3.7. Direito à identidade pessoal, familiar e social" (Revista do Advogado, p. 5, transcrito na palestra no 2o Ciclo de Estudos de Direito Econômico, livro "Estudos de Direito Econômico", ob. cit. p. 132).

${ }^{9}$ Os artigos $73, \S 1^{\circ}$, inciso II, 101, 104, § único, têm a seguinte dicção: "Art. 73 ... $\S 1^{\circ}$ O Os Ministros do Tribunal de Contas da União serão nomeados dentre brasileiros que satisfaçam os seguintes requisitos: ... II. idoneidade moral e reputação ilibada";

"Art. 101 O Supremo Tribunal Federal compõe-se de 11 Ministros, escolhidos dentre cidadãos com mais de 35 e menos de 65 anos de idade, de notável saber jurídico e reputação ilibada";

"Art. 104 ... § único. Os Ministros do Superior Tribunal de Justiça serão nomeados pelo Presidente da República, dentre brasileiros com mais de 35 e menos de 65 anos, de notável saber jurídico e reputação ilibada, depois de aprovada a escolha pelo Senado Federal, sendo: I. 1/ 3 dentre juízes dos Tribunais Regionais Federais e 1/3 dentre desembargadores dos Tribunais de Justiça, indicados em lista tríplice elaborada pelo próprio Tribunal; II. 1/3, em partes iguais, dentre advogados e membros do Ministério Público Federal, Estadual, do Distrito Federal e Territórios, alternadamente, indicados na forma do art. 94", estando o "caput" do art. 37 assim redigido: "A administração pública direta e indireta de qualquer dos Poderes da União, dos Estados, do Distrito Federal e dos Municípios obedecerá aos princípios de legalidade, impessoalidade, moralidade, publicidade e eficiência e, também, ao seguinte: ..." (grifos nossos).

${ }^{10}$ Nada obstante o artigo 5º, inciso XII, da Constituição Federal, assim redigido: "é inviolável o sigilo da correspondência e das comunicações telegráficas, de dados e das comunicações telefônicas, salvo, no último caso, por ordem judicial, nas hipóteses e na forma que a lei estabelecer para fins de investigação criminal ou instrução processual penal", garanta o sigilo de dados, tal sigilo é relativo à luz da exposição pública da internet. 


\section{Ives Gandra da Silva Martins / Rogério Vidal Gandra da Silva Martins}

11 José de Oliveira Ascenção formula quatro questões sobre a nova forma de informação: "1. A sociedade da informação não será também a sociedade da desinformação?

2. A sociedade da informação não será também a sociedade do excesso de informação?

3. A sociedade da informação não será, por outro lado, a sociedade da redução da informação?

4. A sociedade da informação não será também a sociedade da monopolização da informação?" (O direito de autor no ciberespaço, PortugalBrasil ano 2000, p. 102/103).

12 É ainda José de Oliveira Ascenção que, com certo desconsolo, afirma: "Um grande princípio da nossa sociedade é o da liberdade da informação. A informação é livre; quem quer a toma, onde ela se encontrar, e utiliza-a como entender. Isto era considerado básico para a participação sem entraves de todos no diálogo social.

Mas esta, como outras liberdades, está sendo objeto de corrosão contínua.

No domínio do direito autoral surge o chamado direito sui generis sobre as bases de dados. Este é, decididamente, um direito cujo objecto é o próprio dado informativo. A informação passa a ser objecto de direitos, de modo que a sua utilização fica reservada ao consentimento do produtor ou empresário da base de dados - para além evidentemente da limitação já representada pelo próprio acesso condicionado à base de dados.
Mas não há apenas isto. A concentração, a nível mundial, das empresas de comunicação - e, muito mais vastamente, das empresas da sociedade da informação - faz formarem-se grandes blocos, que dominam a comunidade e a informação disponível.

Esse movimento está em marcha, sem que nenhuma atitude esteja a ser tomada, a nível global da disciplina da sociedade da informação, para o contrariar. Muito pelo contrário: no próprio âmbito do direito de autor se combatem ferozmente restrições admitidas pela Convenção de Berna, no sector de radiodifusão, por exemplo, que visavam afastar o abuso de entidades que houvessem adquirido para si posições monopolísticas.

Temos assim que, insensivelmente, da informação livre se passa à informação apropriada ou dominada por grandes conglomerados. Onde havia liberdade passa a haver espaços cada vez maiores de dominação. A informação torna-se objecto de comércio privado e tem o destino de toda a mercadoria.

Isto significa também que a hora do dealbar da sociedade da informação pode ser também a hora do crespúsculo de uma liberdade fundamental: a liberdade da informação" (O direito de autor no ciberespaço, ob. cit., p. 103). 